\title{
THE RELATIONSHIP OF THE ADRENAL, THYROID, AND PITUITARY GLANDS TO THE GROWTH OF HAIR*
}

\author{
By Burton L. Baker $\uparrow$ \\ Department of Anatomy, University of Michigan Medical School, Ann Arbor, Mich.
}

Since hair appears to be one of the most rapidly growing structures of the body, one might expect that it would serve as a sensitive indicator of the modifying action of hormones on general body growth. In this sense, alterations in the rate of growth of hair might be regarded solely as a reflection of any general metabolic changes induced by the hormones. On the contrary, it is possible that hormones modify the growth of hair in a way that is different from the effects which they elicit elsewhere in the body. In other words, is the response of hair to the action of these humoral agents so unique that the piliary system should be regarded as a special target organ? In the following presentation, we shall seek to analyze the effects of hormones on the piliary system in the light of these two alternatives. The rôle played by the secretions of the adrenal, thyroid, and pituitary glands in the regulation of the growth of hair has been investigated chiefly in two forms, the rat and man. Therefore, information which has been derived from study of the rat will be emphasized and an attempt made to correlate these findings with the more limited information which is available concerning the relationship of these glands to hair in man.

\section{The Adrenal Gland}

A general knowledge of the physiology of the adrenal cortex is prerequisite to an understanding of the important regulatory control which it exerts over the piliary system. Some of the steroid compounds which have been isolated from the adrenal cortex may be classified roughly into three groups on the basis of their physiological effects: (1) electrolyte-regulating, (2) carbohydrate-regulating, and (3) androgenic (FIGURE 1). It is established that the adrenal glands of both rat and man secrete compounds belonging to groups 1 and 2. These groups of hormones may be designated as C-11 non-oxygenated, and C-11 oxygenated steroids, respectively, since they differ with respect to the absence or presence of an oxygen atom at the C-11 position of the sterol nucleus. Eleven-desoxycorticosterone is the best known compound of group 1 and acts chiefly on inorganic metabolism, stimulating the excretion of potassium and retention of sodium. In contrast, the members of group 2 are more potent in regulating organic metabolism. They modify several different processes in carbohydrate metabolism, among these effects being the acceleration of gluconeogenesis. When administered in high doses, they cause a breakdown of protein, with loss of nitrogen by excretion.

\footnotetext{
- The original work included in this review was supported by grants-in-aid from the Division of Research Grants and Fellowships, United Sta tes Public Health Service, and from the Upjohn Company.

$\dagger$ The work involving ACTH is being done in collaboration with Dr. Dwight J. Ingle, of the Upjohn Research Laboratories, and $\mathrm{Dr}$. Choh Hao $\mathrm{Li}$, of the University of California. The investigations involving the local application of adrenal compounds and action of estrogens is a collaborative project with Dr. Wayne L. Whitaker of the University of Michigan.
} 
Rather little is known concerning the production of androgenic compounds by the adrenal glands of the adult rat. On the other hand, in man, the adrenal glands do secrete steroids of this type, the level of which may be followed by determination of the 17-ketosteroids in the urine.

It is essential to point out that this grouping of adrenal compounds is empirical and the boundaries between the functions of these substances are by no means sharply defined. For example, 11-desoxycorticosterone will cause some elevation of liver glycogen, if injected in sufficiently high doses. Likewise, the various members of the $\mathrm{C}-11$ oxygenated group vary among

(1)

C-II NONOXYGENATED STEROIDS

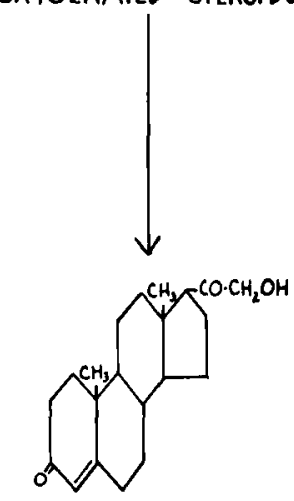

DESOXYCORTICOSTERONE
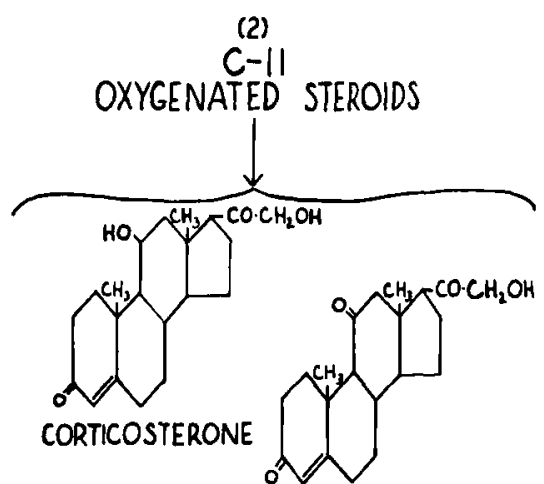

II-DEHYDROCORTICOSTERONE

A

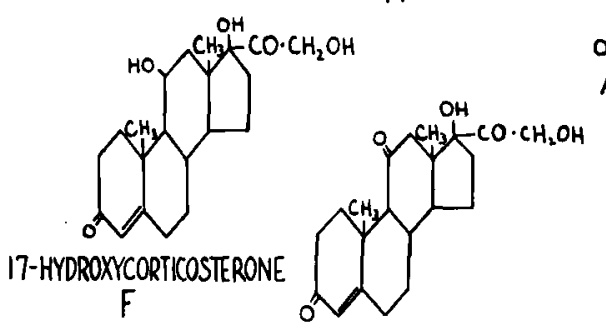

11-DEHYDRO 17-HYDROXYCORTICOSTERONE
(3)

ANDROGENIC STEROIDS

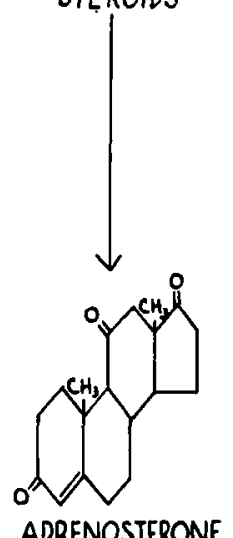

E

Figure 1. Formulae of some of the hormones which have been isolated from the adrenal cortex.

themselves in their effects on both organic and electrolyte metabolism, these effects being modified also by the experimental conditions under which they are studied.

On the basis of several lines of evidence, it appears that, in the rat, the zona glomerulosa and zona fasciculata of the adrenal cortex secrete the electrolyte-regulating and carbohydrate-regulating steroids, respectively. Furthermore, present knowledge indicates that, in the rat, the production of only the latter group is regulated by the anterior hypophysis through its adrenocorticotropic hormone (ACTH). In contrast, most investigators who have studied the problem agree that, in man, the hypophysis regulates the secretion of all three groups of steroids. 
1. The Rat. (a) The Effect of Adrenalectomy. It is of particular interest that when the production of adrenal hormones ceases, due to adrenal ablation, hair grows at a more rapid rate, ${ }^{10,31}$ thus indicating that the adrenal cortex, at its normal level of activity, may inhibit the growth of hair. The epithelium of inactive hair follicles is stimulated to proliferate as early as 2 days following the operation, and, in young underfed rats, hair appears on the surface of the skin within 8 to 9 days. ${ }^{10}$ The extent to which the normal wave-like and cyclic pattern of growth is disturbed was studied by Dieke, ${ }^{15}$ who observed, in the Norway rat, that the interval between the initiation of new cycles is shortened so that adrenalectomized rats start their 6 th cycle at an age when the controls begin their 5th cycle. In our experience, 3 weeks after the operation in normal adult rats, hair is growing much more generally over the body than is normally the case, so that many follicles are activated which otherwise would have remained quiescent.

As would be expected, this accelerated growth is accompanied by important physiologic changes in the skin. Butcher ${ }^{9}$ reports a 39 per cent increase in the oxygen consumption of the skin of underfed rats 66 hours after adrenalectomy. Also, Spoor and Ralli, ${ }^{37}$ by chemical analysis, confirm. the increase in melanin content of the rat skin, following adrenalectomy of rats in which achromotrichia has been induced previously by dietary means. Both the phenol content and reducing power of skin extracts, factors related to melanogenesis, are increased under the conditions of their experiments.

In order to evaluate the significance of acceleration in growth after adrenalectomy, one should know whether the effect is transitory or is maintained. Some evidence is available which indicates that it persists for some time after adrenalectomy. From the data of Dieke, ${ }^{15}$ one would infer that a continuous speeding up of the cycles occurs for 20 weeks post-operatively. Our studies of the growth of hair on the dorsum of the neck have brought us to a similar conclusion. In the normal rat, hair usually grows at one time in limited areas which are separated by regions of inactivity. Only occasionally is general growth observed throughout this region. In these studies, observations are made weekly, and the hair is clipped. Since these rats are black-hooded, the presence of growth is demonstrated by pigmentation of the skin even though hair may not be visible grossly.

Some rats reassume the normal patterns of growth shortly after adrenalectomy. In many of these animals, however, general and continuous growth throughout the area is indicated by the constant presence of cutaneous pigmentation for a period of 11 weeks after the operation. This pigmentation frequently is accompanied by general growth of hair. We never observe similar evidence of persistent general growth of hair in normal rats. Thus, although there is considerable individual variation, a state of accelerated growth may be maintained for a number of weeks after adrenalectomy. Probably, some tapering off of the effect should be expected if observations are continued for a sufficiently long period of time. The part played by the development of accessory adrenocortical tissue in the early recovery of a normal pattern and rate of hair growth in some of our rats remains to be clarified. 
A discordant note is provided by Stein and Wertheimer, ${ }^{38}$ who report an increased loss of hair after adrenalectomy of rats. Accelerated growth might be responsible for this observation. They related this effect to loss of the medulla and found various cortical substances incapable of altering this outcome. However, the increased loss of hair was accompanied by ulceration of the skin. Ulceration of the skin is never observed in our adrenalectomized rats and, to our knowledge, has not been reported by others. Hence, one suspects that uncontrolled factors may be involved in the experiments of these investigators.

(b) The Effect of Experimental Hyperadrenocorticism. Since the C-11 oxygenated steroids are capable of setting up a negative nitrogen balance and retarding general body growth when their concentration in the body is elevated above the normal level, one might expect that they would retard the growth of hair also. Such a condition may be induced by the injection of purified adrenocorticotropin, which increases the production of C-11 oxygenated steroids by the adrenal gland. Treatment of adult male rats with 1 to $3 \mathrm{mg}$. daily for 21 days results in practically complete suppression of growth of hair, this effect becoming evident during the third week of treatment. ${ }^{4}{ }^{29}$ The development of most hair follicles is arrested in the epithelial bud stage. In addition, the tela subcutanea is completely depleted of fat, the epidermis is thinned, and dermal connective tissue becomes more compactly arranged (FIGURES 2 and 3 ). Alkaline phosphatase activity is still present.

Some attempts have been made to elicit similar effects by the parenteral administration of adrenocortical compounds and extracts. No detailed studies are available of the action of pure C-11 oxygenated steroids on the piliary system when given orally or parenterally, although Wells and Kendall $1^{41}$ point out that, in male rats receiving 11-dehydro-17-hydroxycorticosterone in the drinking water, the fur becomes rough and thin. Since desoxycorticosterone acetate (DCA) has little effect on organic metabolism, one would not expect it to be a very potent inhibitor of growth of hair. In fact, Emmens ${ }^{18}$ observes daily doses of $1 \mathrm{mg}$. of this compound, or implantation as pellets, to be ineffective in the rat. Likewise, Houssay and Higgins $^{23}$ report daily injection of doses of DCA, ranging from 0.1 to $1.0 \mathrm{mg}$., to have only a slightly retarding effect on the regrowth of hair in gonadectomized mice of the CBA and C57 strains, On the contrary, Ralli and Graef ${ }^{32}$ find $0.5 \mathrm{mg}$. given daily to be sufficient to suppress growth of hair under different experimental conditions in rats. All workers are agreed that currently available extracts are not very potent inhibitors. Ralli and Graef find such extracts less effective than DCA, and, in our experience, ${ }^{26}$ as much as $5 \mathrm{cc}$. of Upjohn Lipo-adrenal extract a day fails to suppress growth of hair in force-fed rats. It appears that these unimpressive results may be due to insufficient dosage since one rat which was given the equivalent of $50 \mathrm{cc}$. of beef adrenal extract a day by stomach tube for 6 weeks exhibits marked suppression of the piliary system (FIGURES 8 and 9). Of particular interest again is the complete mobilization of subcutaneous fat (FIGURES 4 and 5).

(c) Local Action of Adrenocortical Compounds. When adrenocortical extract 

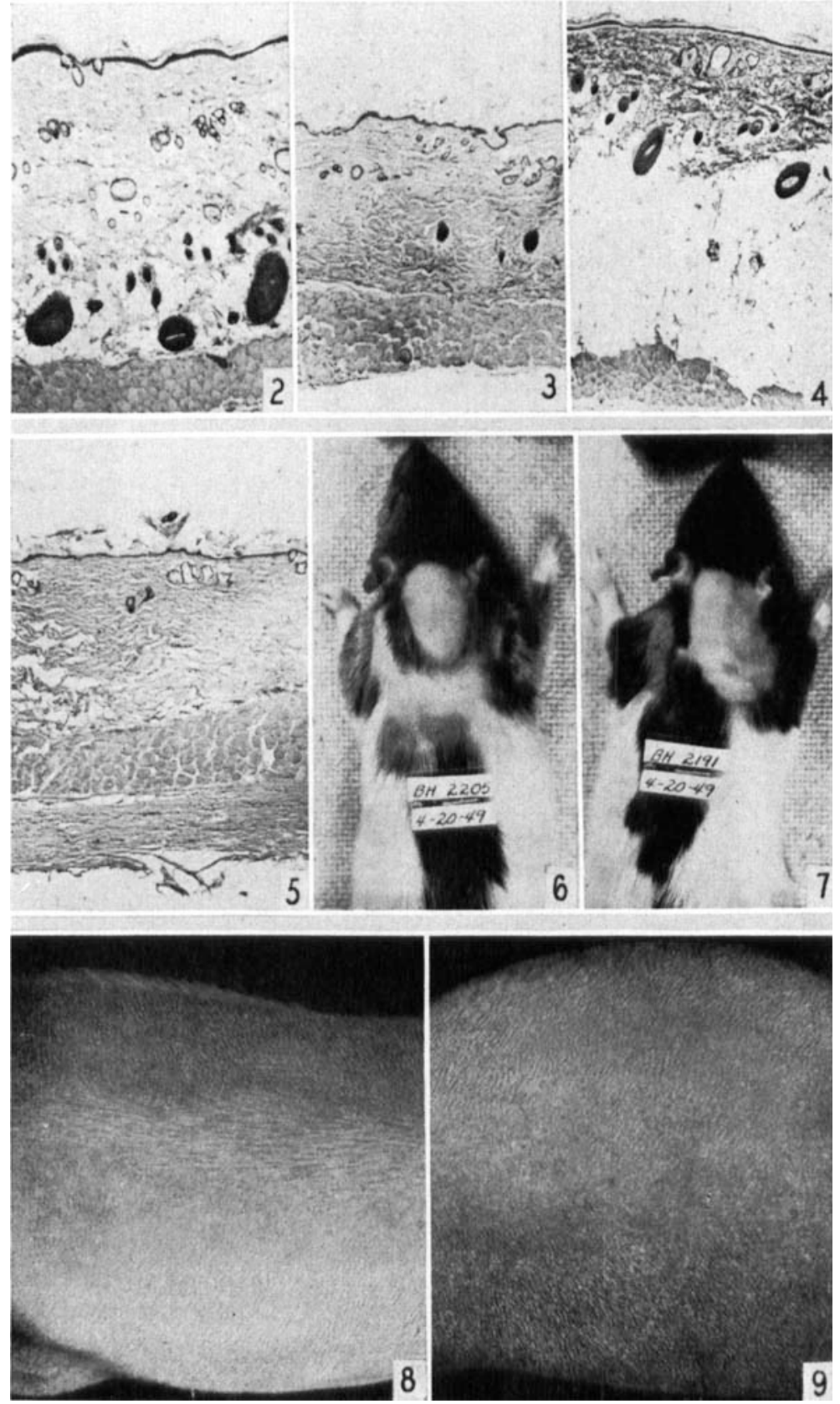

Frgures 2-9 (see facing page). 
is applied to the skin, the growth of hair is arrested, but only in the area of application. In our experiments, the dorsum of the neck is studied, with the hormone being applied caudal to the right ear. The pattern of growth is sketched weekly, and the hair is clipped. In rats which are young and healthy, this pattern is symmetrical. Hence, failure of hair to grow on the right side is indicative of inhibition and, according to our criteria, in order to be considered significant, this state must be maintained for 3 consecutive weeks. Figure 6 illustrates a control to which alcohol was applied, and FIGURE 7 , one receiving $0.1 \mathrm{cc}$. daily of hog adrenal extract.* Inhibition, as indicated by the absence of cutaneous pigmentation, is observed as early as 8 days after the beginning of treatment. Complete local inhibition in male rats may be maintained for about 160 days. In two rats treated for 180 days, however, hair began to grow during the last two weeks of the experiment, in spite of continuation of treatment (FIGURE 13). These are the only animals which have received extract for so long a period of time, and clearly demonstrate that a refractoriness to the local inhibiting action of extracts will develop.

Here, as is the case after systemic treatment with $\mathrm{ACTH}$, samples of skin, taken from areas treated for comparatively short periods, show the hair follicles to be in the epithelial bud stage. ${ }^{3}$ This finding, supplemented by the many weekly observations we have made of the changing patterns of hair growth, indicates that percutaneously applied adrenal hormones are probably more highly inhibitory on follicles in this stage than on those which are growing. The explanation for this observation may rest chiefly on accessibility of the epithelial cells to the surface of the skin, since epithelial buds are in the superficial part of the dermis, in contrast to the growing bulbs which reach into the subcutaneous tissues. Following cessation of treatment, growth of hair is reinitiated promptly, and, subsequent to the second week, a heavy coat grows throughout the area previously treated (FIGURE 18). Subsequently, the normal patterns of growth are regained.

Accompanying this interruption in the growth of hair are certain other changes in the skin, which show that hair is but one of many cutaneous structures affected by the adrenal hormones. If treatment with extract is continued for about 81 days, the epidermis is usually thinner in the area

- The extract used throughout our studies dealing with direct application to the skin is specially prepared by Dr. William J. Haines of the Upjohn Company, to whom we express our appreciation. It is dissolved in 25 per cent alcohol and, by the liver glycogen test, is equivalent to $1 \mathrm{mg}$. of 11-dehydro-17-hydroxycorticosterone per cc.

Figure 2 (see opposile page). Skin of rat, control for animal illustrated in Ficure 3.

Figure 3. Skin of rat which had received $3 \mathrm{mg}$. of ACTH daily for 21 days. The hair follicles are inactive, epidermis is thinned, dermis condensed and tela subcutanea depleted of fat.

FIGURE 4. Skin of rat shown in FICURE 8. Hair is growing. The panniculus adiposus is thick because the oil solvent for the extract was fed by stomach tube.

FIGURE. 5. Skin of rat illustrated in PIGURE 9. This animal was given cortin by stomach tube. Hair follicles are inactive. Subcutaneous fat is completely mobilized.

Figurg 6. Symmetrical pattern of hair growth on a rat treated percutaneously caudal to right ear with 0.1 cc. of 25 per cent alcohol daily for 36 days.

Figure 7. Cessation in growth of hair caudal to right ear due to treatment in this area for 36 days with adrenal extract the daily dose of which by the liver glycogen test is equivalent to $100 \mu \mathrm{g}$. of 11-dehydro-17. hydroxycorticosterone.

Figure 8. One week's growth of hair, control for rat shown in PIGURE 9.

Figure 9. Failure of hair to grow on a rat during the sixth week of treatment with adrenal extract. The preparation was fed by stomach tube and consisted of both hog and beef extract, the daily dose being equivalent to $50 \mathrm{cc}$. of beef adrenal extract. 
of treatment in both sexes. In males, the size of the epidermal cells is reduced (FIGURE 10)." Likewise, some reduction in thickness of the dermis is observed (FIGURE 11) which is not due to the mere absence of growing hair, since, under normal conditions, there is not a statistically significant difference in thickness of the dermis between an area of active hair growth and one of inactivity (FIGURE 12).

Effect of Local Treatment with $100 \mu \mathrm{G}$. Daily of 11-Dehydro-17-HydroxycorticosTERONE OR ITS EQUIVALENT IN Hog ADRENAL EXTRACT ON Epideryal Celi. Size

\begin{tabular}{|c|c|c|c|c|c|c|}
\hline \multirow{2}{*}{ Sex } & \multirow{2}{*}{$\begin{array}{c}\text { No. of } \\
\text { rats }\end{array}$} & \multirow{2}{*}{ Treatment } & \multirow{2}{*}{$\begin{array}{c}\text { Mean } \\
\text { days of } \\
\text { treatment }\end{array}$} & \multicolumn{2}{|c|}{ Mean area $\left(\mu^{2}\right)$} & \multirow{2}{*}{$" t "$} \\
\hline & & & & Left & Right & \\
\hline Male & 7 & ACE; E* & $91 \pm 28.4 \dagger$ & $42.9 \pm 3.0$ & $30.1 \pm 5.3$ & 5.58 \\
\hline Male & 4 & Alc. & $77 \pm 34.3$ & $43.6 \pm 6.2$ & $41.3 \pm 4.8$ & 0.59 \\
\hline Female & 8 & $\mathrm{ACE} ; \mathrm{E}$ & $81 \pm 23.4$ & $38.6 \pm 4.5$ & $36.4 \pm 5.5$ & 0.88 \\
\hline Female & 6 & Alc. & $84 \pm 11.6$ & $37.8 \pm 3.0$ & $38.2 \pm 3.0$ & $\begin{array}{l}\mathrm{P}>.50 \\
0.50\end{array}$ \\
\hline
\end{tabular}

- ACE = Hog adrenal extract; $E$ = 11-dehydro-17-hydroxycorticosterone.

$\uparrow$ Standard deviation.

FigORE 10.

Efrect of Treatment with Extract, 11-Dehydro-17-Hydroxycorticosterone, and 17-Hydroxycorticosterone on Dermal ThickNess

\begin{tabular}{|c|c|c|c|c|c|c|}
\hline \multirow{2}{*}{$\operatorname{Sex}$} & \multirow{2}{*}{$\begin{array}{c}\text { No. of } \\
\text { rats }\end{array}$} & \multirow{2}{*}{ Treatment } & \multirow{2}{*}{$\begin{array}{c}\text { Mean } \\
\text { days of } \\
\text { treatment }\end{array}$} & \multicolumn{2}{|c|}{ Mean thickness $(\mu)$} & \multirow{2}{*}{ " $t$ " } \\
\hline & & & & Left & Right & \\
\hline Male & 19 & $\mathrm{ACE} ; \mathrm{E} ; \mathrm{F}^{*}$ & $49 \pm 37 \dagger$ & $554 \pm 150.2$ & $467 \pm 167.1$ & $\begin{array}{l}1.68 \\
P=.10\end{array}$ \\
\hline $\begin{array}{l}\text { Male } \\
\text { Female }\end{array}$ & $\begin{array}{r}4 \\
22\end{array}$ & $\begin{array}{l}\text { Alc. } \\
\text { ACE; E }\end{array}$ & $\begin{array}{l}57 \pm 31 \\
57 \pm 26\end{array}$ & $\begin{array}{l}400 \pm 87.6 \\
351 \pm 76.4\end{array}$ & $\begin{array}{l}390 \pm 87.6 \\
280 \pm 69.0\end{array}$ & $\begin{array}{l}0.09 \\
3.20 \\
\mathrm{P}\end{array}$ \\
\hline Female & 3 & Alc. & $87 \pm 10$ & $288 \pm 38.4$ & $277 \pm 52.2$ & 0.28 \\
\hline
\end{tabular}

- $\mathrm{ACE}=$ Hog adrenal extract; $\mathrm{E}=11$-dehydro-17-hydroxycorticosterone; $F=17$-hydroxycorticosterone.

t Standard deviation.

Figure 11.

If treatment with this extract is prolonged, atrophy involving all parts of the skin may be induced. These changes are illustrated by samples of skin taken from the right and left sides of the neck of a male rat treated with concentrated extract for 112 days. The epidermis is thinned (FIGURES 16 and 17), and the hair follicles and sebaceous glands are atrophic. The dermis is much thinner and exhibits a loss of discreteness in the outline on the collagenous fibers, these appearing to be fused together. A reduction occurs in the number of fibroblasts, mast cells, and other cellular components of the connective tissue. Glycoprotein in the basement membranes of the epidermis, hair follicles, and sebaceous glands and in the arrectores pilorum 
muscle remains prominent. Elastic fibers are more concentrated. Subcutaneous fat may be wiped out. Do these structural modifications represent permanent damage? Further study will be required in order to answer this question, but the resumption in hair production, regardless of continued local treatment with extract, which was alluded to previously, indicates that the changes described are not irreversible.

Similar inhibition in the growth of hair may be induced by several pure adrenal compounds. For some time, we have been attempting to compare the growth-inhibiting power of the crystalline compounds, using the technique of local application. One might expect that this characteristic would parallel the action of the steroids on organic metabolism, as illustrated by their capacity to increase the glycogen content of liver. The steroids* being studied, listed in the order of their capacity to increase liver glycogen and promote the work output of muscle, include: 17-hydroxycorticosterone (F), 11-dehydro-17-hydroxycorticosterone (E), corticosterone, 11-dehydrocorti-

The Relationship of the Presence or Absence of Growth of Hatr and of Sex TO ThickNesS OF THE DerMis

\begin{tabular}{|c|c|c|c|c|c|}
\hline Sex & $\begin{array}{l}\text { No. with } \\
\text { no hair } \\
\text { growth }\end{array}$ & $\begin{array}{c}\text { Mean thickness } \\
\text { (microns) }\end{array}$ & $\begin{array}{c}\text { No. with } \\
\text { hair } \\
\text { growth }\end{array}$ & $\begin{array}{l}\text { Mean thicknes } \\
\text { (microns) }\end{array}$ & “ \\
\hline Males & 11 & $511.1 \pm 196^{*}$ & 12 & $542.1 \pm 130.3$ & 0.45 \\
\hline \multirow[t]{2}{*}{ Females } & \multirow[t]{2}{*}{14} & $335.1 \pm 73$ & \multirow[t]{2}{*}{11} & $353.4 \pm 80.2$ & \multirow[t]{2}{*}{$\begin{array}{l}0.60 \\
P>.05\end{array}$} \\
\hline & & $\begin{array}{c}" t "=3.11 \\
P<.01\end{array}$ & & $\begin{array}{c}\text { "t" }=4.13 \\
P<.01\end{array}$ & \\
\hline
\end{tabular}

- Standard deviation.

FtGURE 12.

costerone acetate (A), 11-desoxycorticosterone acetate, and 17-hydroxy-11desoxycorticosterone (S).

This investigation is still incomplete because of the many unexpected problems which arose. Nevertheless, it is clear from our studies that the C-11 oxygenated steroids are more potent growth inhibitors than the C-11 non-oxygenated group. Furthermore, it appears that 17-hydroxycorticosterone and 11-dehydro-17-hydroxycorticosterone are the most potent, with the former hormone being somewhat superior. With these compounds, inhibition may be induced by daily doses in the neighborhood of $10 \mu \mathrm{g}$. Thus, in so far as our comparative studies have progressed, there appears to be some parallelism between the capacity of a compound to increase liver glycogen and inhibit growth, and that possibly these two actions may be dependent on a common process. It should be recalled that the $\mathrm{C}-11$ oxygenated compounds are capable of inducing a negative nitrogen balance when administered parenterally. Whether the loss of nitrogen is due to

\footnotetext{
- We wish to express our appreciation to Drs. M. H. Kuizenga and W. J. Haines of the Upjohn Company for 17-hydroxycorticosterone, to Dr. J. M. Carlisle of Merck and Company for 11-dehydrocorticosterone acetate, and to Dr. Edward Henderson of the Schering Corporation for 11-desoxycorticosterone acetate.
} 

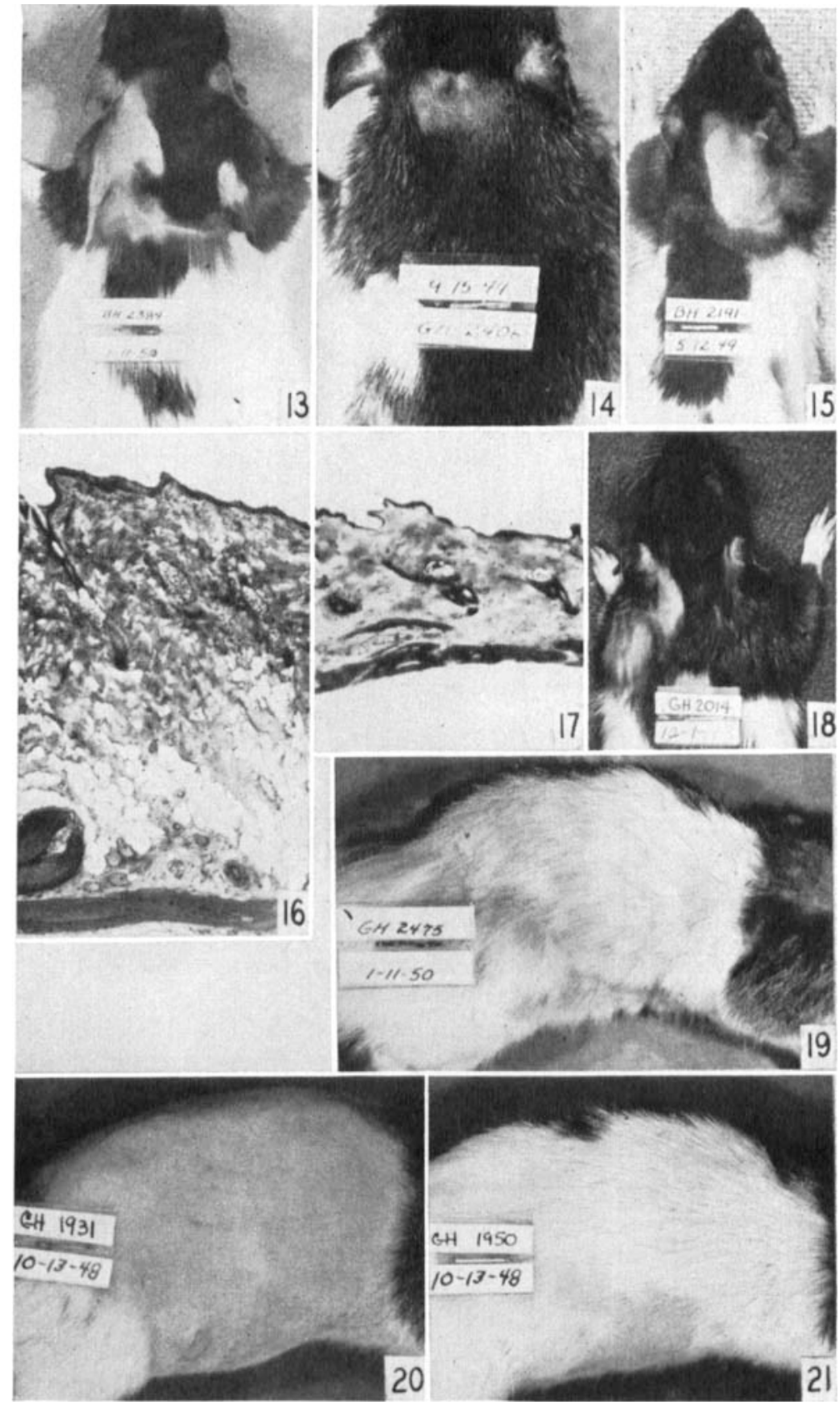

Frourrs 13-21 (seo facing page) 
excessive catabolism or impaired anabolism is not known definitely, but the recent work of Enge ${ }^{19}$ indicates that the adrenal compounds act directly on protein to cause its breakdown. From a chemical standpoint, the presence of an oxygen atom at the C-11 position, and of a hydroxyl group at the C-17 position of the sterol nucleus, seems to have an important relationship to the growth-inhibiting activity of the compound.

The activity of a compound, when administered percutaneously, is conditioned by the vehicle in which it is dissolved. As is true of the sex hormones, ${ }^{17}$ absorption seems to be facilitated if volatile organic solvents are employed. For example, whereas desoxycorticosterone acetate and 11-dehydrocorticosterone show some local growth-inhibiting action when administered in alcohol, they are completely inert if the same doses are applied in oil.

(d) Relationship to Other Inhibiting Factors. Reduction of food intake, ${ }^{10}$ maintenance on diets deficient in the filtrate factors of the vitamin B complex ${ }^{31}$ and administration of high doses of estrogen ${ }^{5,22,44}$ will retard growth of hair in the rat. Involvement of the adrenal cortex is indicated by the fact that, in each of these circumstances, if adrenalectomy is performed, growth of hair is resumed in spite of continued subjection of the rat to the original inhibiting factor ${ }^{5}, 10,31$ (FIGURES 20 and 21). This stimulation is indeed dramatic. Repeatedly in our laboratories we have seen rats debilitated and sick from the toxic effects of intense treatment with estrogens but with hair growing profusely all over the body as a result of adrenalectomy performed 3 weeks previously.

We are seeking to discover the precise manner in which the adrenal gland participates in the suppression of the piliary system in these situations, focusing our attention chiefly on the action of estrogen. It is entirely possible that a similar mechanism comes into play if the animal is denied food or B vitamins.

Many lines of investigation show that systemic administration of estrogens, particularly in high doses, will stimulate the anterior hypophysis to release ACTH and thus activate the adrenal cortex. Hence, when estrogen is observed to be incapable of maintaining suppression of hair growth after

FIGURE 13 (see opposite page). Growth of hair is resumed in spite of daily treatment with extract on the right side of the neck for 180 days.

FIGURE 14. This rat was treated daily percutaneously caudal to the right ear with $100 \mu \mathrm{g}$. of alpha-estradiol until generalized inhibition of hair growth was induced. Adrenalectomy was performed and treatment continued. This growth during the third post-operative week shows no inhibition by estrogen in the area of treatment.

FIGURE 15. This rat was treated similarly to that shown in Figure 14 except that adrenal extract was substituted for the estrogen. Local inhibition is induced in spite of adrenalectomy. This is the rat shown in FIGURE 7 but three weeks later, adrenalectomy having been performed on the date of the previous photograph.

FigURE 16. Skin from left, non-treated side of neck. The specimen shown in FIGURE 17 was taken from the right side of the neck of the same rat.

FIGURE 17. Skin from right side of neck in area treated daily with 0.1 cc. of adrenal extract for 112 days. Hair follicles, epidermis and sebaceous glands are atrophic. The dermis is thinned and subcutaneous fat is completely absent.

FIGURE 18. Re-growth of hair on the right side of neck during the fifth week after cessation of daily treatment with $100 \mu \mathrm{g}$. of 11-dehydro-17-hydroxycorticosterone. The rat was treated for 6 weeks, during this period growth of hair being inhibited completely in this area for 4 consecutive weeks.

FIGURE 19. Growth of hair on the side of the body during the twenty-fifth week after hypophysectomy.

Figure 20. Failure of hair to grow during seventh week of daily subcutaneous injection of $50 \mu \mathrm{g}$. of alphaestradiol dipropionate.

FIGURE 21. This rat was treated in the same manner as that shown in Figure 20, except that adrenalectomy was performed 3 weeks previously. Growth of hai $r$ is resumed in spite of continued treatment with the estrogen. 
adrenalectomy, one might assume that the anterior hypophysis and adrenal cortex mediate the growth-inhibiting action of estrogens (route D of FIGURE 22). The problem is much more complex, however, and the other possible mechanisms illustrated in this figure must be considered.

If estrogens can inhibit growth of hair by direct action on the hair follicle (A), then the theory of mediation by the adrenal cortex could be abandoned. Williams, Gardner, and DeVitat2 report inhibition to follow percutaneous application of estrone to the skin of the dog. We have attempted to reproduce these results in the rat by using alpha-estradiol and

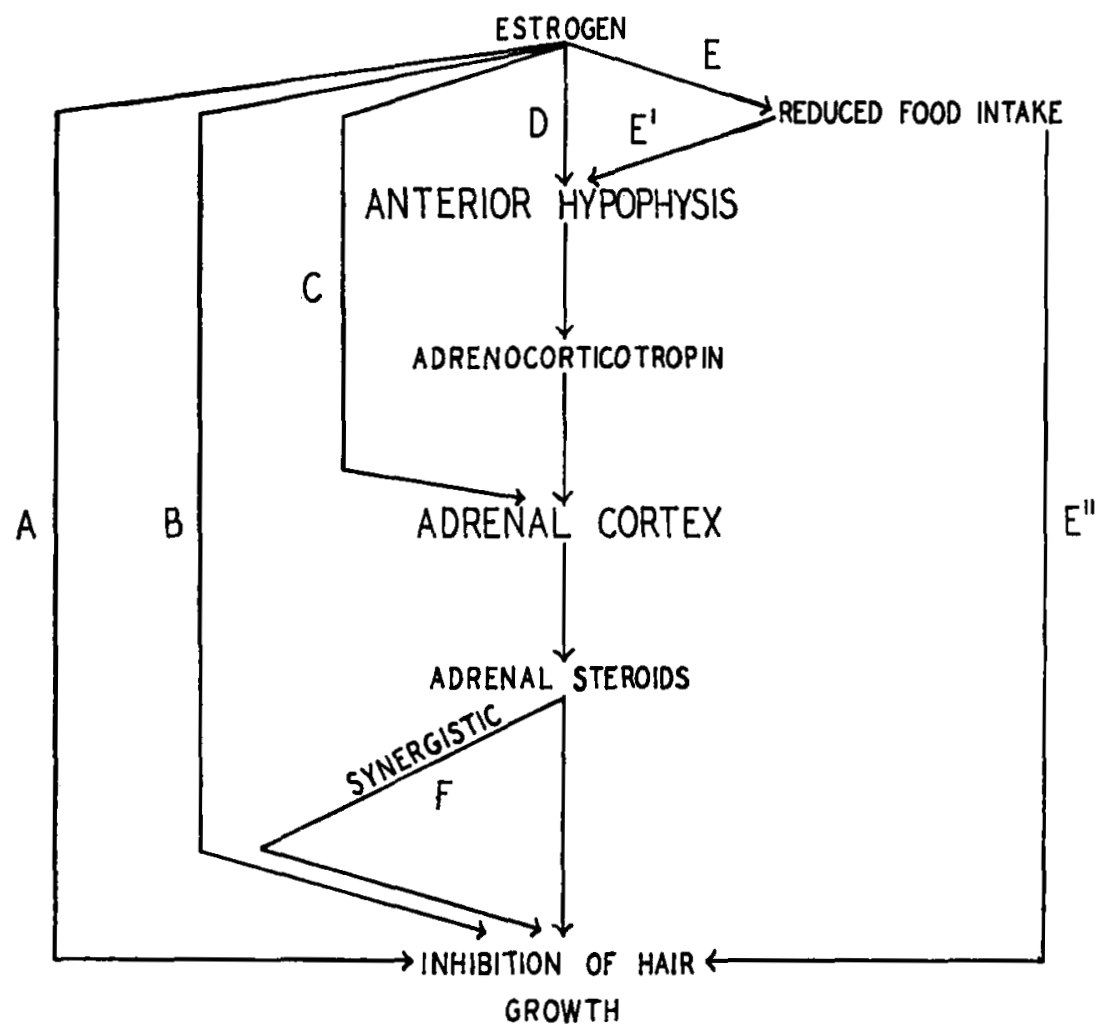

Fucuge 22. Possible ways in which estrogen might inhibit the growth of hair.

estrone in alcoholic solutions, with and without the addition of small amounts of sesame oil. The doses employed range from 1 to $100 \mu \mathrm{g}$. per day. The technique of local application used in the study of adrenal hormones is followed here, and, in addition, the growth of hair is observed on the side of the body for evidence of systemic inhibition. The estrogen is absorbed into the blood stream and the higher doses produce a generalized retardation in growth throughout the areas observed. Although hair frequently does not grow in the area of application, failure of hair to grow elsewhere makes it impossible for us to detect a clear-cut local action 
by this procedure. Prolongation of treatment does not always maintain inhibition in the area of treatment. Thus, it is shown that, under these conditions, a local inhibitory action by estrogen cannot be divorced from its systemic effects. The possibility exists that the generalized suppression of growth of hair may mask the local effect of the estrogen.

Does estrogen inhibit growth of hair indirectly by causing a reduction in food intake (route $\mathrm{E}$ of FIGURE 22)? Hooker and Pfeiffer, ${ }^{22}$ in paired feeding experiments, conclude that reduction in food intake is not prerequisite to the effectiveness of estrogen. When estrogen is administered by injection in our experiments, it suppresses growth of hair in rats fed by stomach tube, so that this factor may be eliminated.

Finally, do adrenal hormones facilitate or potentiate the growth-inhibiting action of estrogens in the peripheral tissues (routes $B$ and F of FIGURE 22)? The critical work of Ingle first demonstrated the potentiating action of adrenal secretions on the diabetogenic action of estrogen. Subsequent investigations by him and others since have led to the development of one of the most important basic concepts in the field of adrenal physiologythat adrenal hormones serve to prepare the body tissues for mobilization by the action of strogen or other agents. In collaboration with Dr. Dwight J. Ingle of the Upjohn Research Laboratories, we are examining this hypothesis with respect to the action of estrogen on hair, by attempting to suppress growth of hair in force-fed adrenalectomized rats by injecting estrogen along with adrenal extract, the latter being injected at a dosage which, by itself, is not significantly inhibitory. These studies are not completed, but as of the moment, estrogen is proving to be effective in inhibiting growth of hair in the adrenalectomized rat, if an optimal amount of extract is administered concurrently.

Thus, it appears that the adrenal cortex may act to make the peripheral tissues responsive to the growth-retarding action of estrogen. This conclusion does not eliminate the possibility that some of the inhibition of growth which follows parenteral administration of estrogen is mediated by the hypophysis and adrenal cortex. Another disturbing factor remains. This is the failure of large doses of estrogen to maintain inhibition locally in the rat by percutaneous application. Can it be that, in these experiments, the endogenous production of adrenal hormones is insufficient to keep their concentration high enough in the area of application to facilitate the action of estrogen? The essential rolle played by adrenocortical hormones in the possible local growth-inhibiting action of estrogen is illustrated by the following experiment. Adrenal extract in amounts equivalent to $100 \mu \mathrm{g}$. of compound $\mathrm{E}$ was applied daily to the skin caudal to the right ear in one group of rats. A second group received $100 \mu \mathrm{g}$. of alpha-estradiol daily in a similar manner. Treatment was continued until inhibition of growth of hair was observed in both groups. As pointed out previously, the growth retardation was general in the estrogen-treated animals and local in those given extract. Then adrenalectomy was performed and treatment continued. In spite of the stimulation of growth which followed, the extract maintained a state of inhibition in the treated area (FIGURE 15), whereas the estrogen was completely ineffective (FIGURE 14). 
(e) Specificity of Inhibition by Adrenal Hormones. The inhibition ingrowth of hair which occurs during systemic treatment with ACTH and adrenal compounds appears to be an over-dosage effect. Likewise, when growth is inhibited locally by direct application of hormones to the skin, it is probable that an abnormally high concentration of hormones is created in that area. If inhibition results from the production of such an abnormal physiological state, then one must consider the possibility that the effect is non-specific. Certainly, no definite solution to this problem, with respect to the adrenal hormones, is now apparent and space does not permit consideration of all pertinent investigations. The following evidence might be cited, however, which shows that the regulatory influence of adrenal hormones over growth of hair is at least different from that exerted by other hormones. First, in so far as is known, the removal of no other endocrine gland results in over-growth of hair in the rat. Also, this finding may be interpreted to indicate that the normal level of adrenal hormones exerts a retarding influence on the growth of hair. Second, since adrenal hormones are locally active in inhibiting growth of hair without producing systemic effects when applied to the skin, the chance that other glands or organs may be the mediators of a non-specific action is eliminated. Admittedly, the possibility still exists that they might participate indirectly in a non-specific effect. Third, the varying potencies of the adrenal compounds, in inhibiting growth locally, suggest the existence of a correlation with the chemical structure of the hormones. Fourth, to our knowledge, there is no other substance or group of substances which will stop the growth of hair locally without damaging the skin. Testosterone propionate, cholesterol, cholic acid, and thyroxine, in concentrations considerably above the minimal effective dose of the C-11 oxygenated steroids, are not inhibitory. Estrogens stand as a possible exception, but the hypothesis that they, too, inhibit grow th by local action requires additional investigation.

(2) Man. Information derived from the study of the relationship of the adrenal glands to the piliary system in lower mammals cannot be transferred to man without considerable modification. This situation is due to the greater control exerted by sex hormones over the grow th and distribution of hair in man and probably, also, to the capacity of the human adrenal cortex to produce substances identical or physiologically similar to the sex steroids. No attempt will be made here to survey the extensive array of clinical syndromes accompanied by disturbance of the piliary system in which there is possible involvement of the adrenal gland. Rather, we shall attempt only to draw some general conclusions from this body of knowledge.

Growth of pubic, axillary, and facial hair may be regarded as a secondary sex characteristic. A state of adrenal insufficiency, whether due to bilateral adrenalectomy ${ }^{24}$ or Addison's disease, ${ }^{26,30}$ is accompanied by reduction in the amount of pubic and axillary hair. Two concepts have been presented to explain this occurrence. Albright ${ }^{1}$ holds that the production of pubic hair in females is controlled by the " $N$ " hormone (one having androgenic properties) of the adrenal cortex. Some of the evidence marshalled by him follows. (1) Patients with primary ovarian insufficiency have reduced axil- 
lary and pubic hair and a low 17-ketosteroid excretion. (2) Administration of estrogen therapy to such patients restores this hair, supposedly by stimulating the pituitary-adrenal axis and the output of " $N$ " hormones by the latter gland. (3) The topical application of testosterone to the axilla will stimulate the growth of hair in the area of treatment. (4) The 17-ketosteroid excretion rises at puberty in females and may be considered to be an index of the secretion of androgenic steroids by the adrenal cortex. Thus, the growth of hair at this time may be controlled by the adrenal gland rather than by the ovaries. (5) Besides Addison's disease, in panhypopituitarism, myxedema, and old age, loss of pubic and axillary hair occurs in association with a low excretion of 17-ketosteroids in the urine.

A second concept, presented by Mussio Fournier et al. ${ }^{80}$ suggests that estrogens control growth of hair in the pubic and axillary areas, but that their action must be synergized by adrenocortical hormones. This conclusion is based on the greatly reduced pubic and axillary hair observed in a woman with Addison's disease, but who presented evidence of continued production of estrogens by the ovary. Also, a case of Addison's disease with similar characteristics is described by Kepler et al. ${ }^{26}$ The growth of pubic and axillary hair in eunuchs castrated before the time of puberty ${ }^{26}$ is pertinent.

In contrast to this loss of hair resulting from adrenal insufficiency is the hypertrichosis which accompanies clinical syndromes involving hyperactivity of the adrenal cortex. Adrenocortical neoplasms may produce this condition. Cushing's disease is accompanied by masculine distribution and overgrowth of hair in women and boys. In the adrenogenital syndrome of women, one may find growth of hair on the upper lip, chin, and other areas of the body, baldness, and assumption of the male configuration by the pubic hair. ${ }^{34}$ Excessive androgen production by the adrenal glands is regarded as the cause of this situation. A satisfactory correlation of these findings with those described previously in animals is most difficult at this time. The picture is complicated by the development of mild hirsutism in cases of rheumatoid arthritis treated with 11-dehydro-17-hydroxycorticosterone. ${ }^{21}$ This compound is not known to be strongly androgenic in rodents, and the stimulation of growth of hair in man is quite contrary to its inhibitory action in lower mammals. Therefore, it may be expected that, when injected into man, (1) 11-dehydro-17-hydroxycorticosterone is converted into another substance having androgenic properties, (2) that the endogenous steroid hormone secretion is unbalanced in favor of greater secretion of substances with androgenic properties, or (3) that the hair follicles of man respond to this compound in an entirely different way than do those of the rat.

An additional point of difference between man and rodents, with respect to the relationship of the adrenocortical hormones to hair, is the failure of these substances to inhibit the growth of hair when applied percutaneously to human beings. In our hands, adrenal extract in alcoholic solutions or in a cream is ineffective. One must keep in mind, however, that there is no assurance that, when applied percutaneously, comparable amounts of 
hormone reach the growing parts of the hair follicle in man, as compared with the rat. In man, the skin is much thicker and the cyclic nature of hair growth is different, so that the difficulties attendant upon effective therapeutic use of adrenal compounds, in controlling hypertrichosis, are amplified greatly.

\section{The Thyroid Gland}

Thyroidectomy of animals causes a reduction in the rapidity with which hair grows back after clipping. ${ }^{12,}$ 18, 18 Furthermore, Dieke ${ }^{15}$ has observed a progressively greater delay in the time of initiation of successive cycles, accompanied by a reversal in direction of spread of the wave of growth. Administration of thyroxine to thyroidectomized rats restores the normal rate of growth but, if this hormone is given in excess, then suppression results from the hyperthyroid state so induced..$^{12}$ If hair follicles are brought to a state of inactivity by underfeeding, thyroxine will reactivate them. ${ }^{7}$ Chang reports that administration of thyroxine to intact rats exerts a variable effect on growth of hair, but if treatment is continued long enough, suppression will occur.

Since there is uniform agreement that thyroidectomy retards growth of hair, it might be expected that administration of antithyroid drugs, which induce a state of physiological thyroidectomy, would have a similar effect. The studies of Dieke, ${ }^{14}$ however, demonstrate a great divergence in the effects of these drugs on the piliary system. Thus, in the doses employed, thiourea has no effect, phenyl thiourea suppresses pigment formation without affecting growth of hair, while alpha-naphthyl thiourea suppresses both hair and pigment formation.

Does the thyroid hormone act directly on the hair apparatus, or by primary modification of the nutritional state of the animal? Observations in our laboratory indicate that different strains of rats vary widely with respect to the magnitude of the retardation in growth of hair after thyroidectomy. This difference seems to be correlated with the natural vigor of the animal. For example, the post-thyroidectomy retardation in growth of hair in the Long-Evans strain is minimal, whereas many Wistar rats grow very little hair after this operation. In our laboratory, the former is much the hardier of the two strains. Chang, ${ }^{12}$ on the basis of very limited observations, concludes that the thyroid hormone acts directly on the hair follicle since treatment of under-nourished rats accelerates the rate of growth of hair in spite of continued loss in body weight. Additional study is needed to clarify this point.

\section{The Hypophysis}

Hypophysectomy of the rat produces a considerable alteration in the normal development of the pelage. Smith ${ }^{35}$ first pointed out that the hair of these animals remains infantile in type. A general slowing down in the rate of growth is demonstrated by Dieke, ${ }^{15}$ who observes a progressively greater delay in the time at which successive cycles begin. Snow and Whitehead ${ }^{38}$ find the weight of hair produced per sq. $\mathrm{cm}$. of body surface 
to be 70 per cent of normal. These observations are impressive, but it should be emphasized that the hypophysectomized rat does grow a considerable amount of hair, as shown by FIGURE 19, which illustrates the growth of hair which occurred during the twenty-fifth week after hypophysectomy. In general, the wave-like pattern of growth which characterizes the normal rat is retained for some time. Replacement therapy with crude extracts containing the growth hormone or implants of the hypophysis will restore the rate and character of growth of hair to normal ${ }^{35,}, 36,40$ and, according to Snow and Whitehead, the amount of hair produced may be increased beyond normal. Pituitary extracts have not proven to be of significant value in the treatment of some types of alopecia in man. ${ }^{27}$

\section{Discussion}

As pointed out in the introduction, it is desirable to ascertain whether the modifications induced in growth of hair by these hormones are specific effects, or only reflections of general metabolic alterations. In general, variations in the rate of hair and body growth run parallel in most of the experimental situations which have been described. Thus, in rats, growth of both hair and other parts of the body is retarded in states of hypothyroidism, hyperthyroidism, hypopituitarism, and hyperadrenocorticism. Hence, it may be concluded that most of these responses to endocrine influences are reflections of general metabolic actions. On the contrary, two reactions stand out which seem to place the responsiveness of hair in a unique category. The first is the acceleration in rate of growth of hair which follows adrenalectomy. This occurs regardless of the physical condition of the animal. One has only to observe the prolific growth of hair on a sick adrenalectomized rat to be impressed with this fact. In contrast, adrenalectomy in young rats stops general body growth. ${ }^{20}$ In only two other tissues, lymphoid tissue ${ }^{23}$ and the epiphyseal cartilage of the tibia, ${ }^{43}$ has evidence of overgrowth after adrenalectomy been observed.

Concerning this response on the part of lymphoid tissue, there is disagreement, ${ }^{39}$ and, in the case of cartilage, it is not as impressive as in the case of hair. Thus, in the rat, hair responds to adrenalectomy in a way that has no exact parallel among the other body tissues. Prerequisite to an accurate analysis of this problem is the availability of more precise information regarding the rate of mitotic proliferation in the growing part of the hair follicle, as compared with that in other tissues. Thus, is there a tendency towards overgrowth in all tissues of the body after adrenalectomy, with the effect becoming most evident in those tissues which normally exhibit the highest rate of cell division?

Secondly, that hair should grow so extensively, even though at a reduced rate in the hypophysectomized rat, seems unusual in view of the very low level of proliferation which characterizes other parts of the body. Can it be that hair continues to grow because hypophysectomy causes atrophy of the zona fasciculata in the adrenal cortex, reducing production of the C-11 oxygenated steroids, and thus creating a state of partial adrenal insuffciency? 
In conclusion, one may expect that any agent which retards or promotes growth of the body as a whole will exert parallel effects on hair. Nevertheless, there seems to be sufficient individuality in the response of hair to some hormonal imbalances for future research to be directed profitably toward discovering the extent to which the hair apparatus should be regarded as a special end-organ for at least some of the hormones which affect it.

\section{Bibliography}

1. Albright, F. 1947. The effect of hormones on osteogenesis in man. Recent Progress in Hormone Research 1: 293. Academic Press. New York.

2. BAKER, B. L. 1949. Anatomical modifications induced by adrenocortical secretions with special reference to the regulation of growth. A.A.A.S. Symposium on the Adrenal Cortex. In press.

3. BAKER, B. L. \& W. L. Whitaker. 1948. Growth inhibition in the skin following direct application of adrenal cortical preparations. Anat. Rec. 102: 333.

4. Baker, B. L., D. J. INGLe, C. H. LI, \& H. M. Evans. 1948. Growth inhibition in the skin induced by parenteral administration of adrenocorticotropin. Anat. Rec. 102: 313 .

5. BAKER, B. L. \& W. L. Whitaker. 1949. Relationship of the adrenal cortex to inhibition of growth of hair by estrogen. Am. J. Physiol. 169: 118.

6. Butcher, E. O. 1937. Hair growth in adrenalectomized, and adrenalectomized thyroxin-treated rats. Am. J. Physiol. 120: 427.

7. Butcher, E. O. 1940. The effects of irritants and thyroxin on hair growth in albino rats. Am. J. Physiol. 129: 553.

8. Butcher, E. O. 1941. Accelerated hair growth in the rat after adrenalectomy cannot be attributed to the thyroid. Proc. Soc. Exp. Biol. and Med. 43: 120 .

9. BUTCHER, E. O. 1943. Oxygen consumption of skin and hair growth after adrenalectomy in the white rat. Endocr. 32: 493 .

10. Butcher, E. O. \& R. A. Richards. 1939. The relation of the adrenals to the retarded hair growth in underfed albino rats. Endocr. 25: 787.

11. Castor, C. W. \& B. L. Baker. Unpublished.

12. Chang, H. C. 1926. Specific influence of the thyroid gland on hair growth. Am. J. Physiol. 77: 562 .

13. Chang, H. C. \& T. P. Feng. 1929. Further studies on thyroid and hair growth Chin. J. Physiol. 3: 57.

14. DIEkE, S. 1947. Pigmentation and hair growth in black rats as modified by the chronic administration of thiourea, phenyl thiourea an $\rfloor$ alpha-naphthyl-thiourea. Endocr. 40: 123.

15. DrEKE, S. 1948. The effect of removing various endocrine glands on the hair cycles of black rats. Endocr. 42: 315 .

16. Dorfman, R. I. 1949. The bioassay of adrenal cortical steroids. Ann. N. Y. Acad. Sci. 50: 556.

17. EMMans, C. W. 1940. The inunction of sex hormones on the skin. J. Endocr. 2: 368 .

18. Emmens, C. W. 1942. The endocrine system and hair growth in the rat. J. Endocr. 3: 64 .

19. ENGEL, F. L. 1949. Studies on the nature of the protein catabolic response to adrenal cortical extract. Accentuation by insulin hypoglycemia. Endocr. 45: 170.

20. Hartman, F. A. \& G. W. ThorN. 1930. A biological method for the assay of cortin. Proc. Soc. Exp. Biol. \& Med. 28: 94.

21. Hench, P. S., E. C. Kendall, C. H. Slocum, \& H. F. Polley. 1949. The effect of a hormone on the adrenal cortex (17-hydroxy-11-dehydrocorticosterone: Compound $\mathrm{E}$ ) and of pituitary adrenocorticotropic hormone on rheumatoid arthritis; preliminary report. Proc. Staff Meet., Mayo Clinic. 24: 181.

22. Hooker, C. W. \& C. A. PFeiffer. 1943. Effects of sex hormones upon body growth, skin, hair and sebaceous glands in the rat. Endocr. 32: 69.

23. HousSAY, A. B. \& G. M. Higgnss. 1949. Hormonal influences upon the rate of growth of hair in gonadectomized mice. Proc. Staff Meet., Mayo Clinic, 24: 597.

24. HugGrNs, C. A. \& W.W. ScotT. 1945. Bilateral adrenalectomy in prostatic cancer. Ann. Surg. 122: 1031.

25. INGLE, D. J. \& B. L. BAKER. Unpublished. 
26. Kepler, E. J., G. A. Peters, \& H. L. MAson. 1943. Addison's disease associated with pubic and axillary alopecia and normal menses. J. Clin. Endocr. 3: 497.

27. Lord, L. W. 1933. Anterior lobe pituitary extract in the treatment of alopecia. Arch. Derm. \& Syph. 28: 381.

28. Martin, L. \& M. Hynes. 1948. Clinical Endocrinology. The Blakiston Co. Philadelphia.

29. Moon, H. D. 1937. Inhibition of somatic growth in castrate rats with pituitary extracts. Proc. Soc. Exp. Biol. \& Med. 37: 34.

30. Mussio Fournier, J. C., E. Pollack, \& J. J. Lussich Siri. 1949. Loss of axillary and pubic hair in a patient with Addison's disease and regular menstruation. $J$. Clin. Endocr. 9: 555.

31. Ralli, E. P. \& I. Graef. 1943. Stimulating effect of adrenalectomy on hair growth and melanin deposition in black rats fed diets adequate and deficient in the filtrate factors of vitamin B. Endocr. 32: 1 .

32. Ralli, E. P. \& I. Graef. 1945. The effects of the synthetic and natural hormone of the adrenal cortex on melanin deposition in adrenalectomized black rats fed diets adequate and deficient in the filtrate factors of vitamin B. Endocr. 37: 252 .

33. Reinharde, W. O. \& R. O. Holmes. 1940. Thymus and lymph nodes following adrenalectomy and maintenance with $\mathrm{NaCl}$ in the rat. Pror. Soc. Exp. Biol. \& Med. 45: 267.

34. SELye, H. 1947. Textbook of Endocrinology. Acta Endocrinologica. Montreal.

35. Sмiтh, P. E. 1930. Hypophysectomy and replacement therapy in the rat. Am. J. Anat. 45: 205.

36. Snow, J. S. \& R. W. Whitenead. 1935. Relationship of the hypophysis to hair growth in the albino rat. Endocr. 19: 88.

37. SpOOR, H. J. \& E. P. Ralli. 1944. Chemical studies on melanogenesis in normal and adrenalectomized rats. Endocr. 35: 325.

38. Stein, L. \& E. Wertheimer. 1941. Hair loss as deficiency test of medullectomy in rats. J. Endocr. 2: 418 .

39. StOERK, H. C. 1944. Thymus weight in relation to body weight in castrated and adrenalectomized rats. Endocr. 34: 329.

40. Thompson, K. W. \& D. W. GaIsEr. 1932. The effect of diet and pituitary growth hormone on hypophysectomized rats. Yale J. Biol. and Med. 4: 677.

41. Wells, B. B. \& E. C. Kendall. 1940. The influence of corticosterone and $\mathrm{Cl} 7$ hydroxydehydrocorticosterone (Compound E) on somatic growth. Proc. Staff Meet., Mayo Clinic, 15: 324.

42. Williaks, W. L., W. U. Gardner, \& J. DeVIta. 1946. Local inhibition of hair growth in dogs by percutaneous application of estrone. Endocr. 38: 368 .

43. Wyman. L. C. \& C. Tum-Suden. 1945. The effect of adrenalectomy on the epiphyseal cartilage of the rat. Fndocr. 36: 340 .

44. ZONDEK, B. 1936. The inhibitory effect of follicular hormone on the anterior lobe of the pituitary gland. Lancet 1: 10. 